\title{
Past lake shore dynamics explain present pattern of unidirectional introgression across a habitat barrier
}

\author{
Kristina M. Sefc • Karin Mattersdorfer • \\ Caroline M. Hermann • Stephan Koblmüller
}

Received: 21 January 2016/Revised: 6 April 2016/Accepted: 18 April 2016/Published online: 9 May 2016

(C) The Author(s) 2016. This article is published with open access at Springerlink.com

\begin{abstract}
Introgression patterns between divergent lineages are often characterized by asymmetry in the direction and among-marker variation in the extent of gene flow, and therefore inform on the mechanisms involved in differentiation and speciation. In the present study, we test the hypothesis that unidirectional introgression between two phenotypically and genetically distinct lineages of the littoral, rockdwelling cichlid fish Tropheus moorii across a wide sandy bay is linked to observed differences in mate preferences between the two lineages. This hypothesis predicts bi-directional nuclear gene flow and was rejected by congruent patterns of introgression in mtDNA, AFLP and microsatellite markers, with admixture confined to the populations west of the bay. This pattern can be explained on the basis of habitat changes in the course of lake level fluctuations, which first facilitated the development of a symmetric
\end{abstract}

Guest editors: S. Koblmüller, R. C. Albertson, M. J. Genner, K. M. Sefc \& T. Takahashi / Advances in Cichlid Research II: Behavior, Ecology and Evolutionary Biology

Electronic supplementary material The online version of this article (doi:10.1007/s10750-016-2791-x) contains supplementary material, which is available to authorized users.

K. M. Sefc · K. Mattersdorfer - C. M. Hermann ·

S. Koblmüller $(\bowtie)$

Institute of Zoology, University of Graz, Universitätsplatz

2, 8010 Graz, Austria

e-mail: stephan.koblmueller@uni-graz.at admixture zone including the area corresponding to the present sand bay and then shaped asymmetry by causing local extinctions and cessation of gene flow when this area became once more inhabitable. This conforms with previous assumptions that habitat dynamics are a primary determinant of populationlevel evolution in Tropheus. In this respect, Tropheus may be representative of species whose preferred habitat is subject to frequent re-structuring.

Keywords Asymmetric introgression . Hybridization - Lake Tanganyika - Tropheus . Population structure $\cdot$ Environmental change

\section{Introduction}

Patterns of introgression between diverging lineages inform about mechanisms involved in differentiation and speciation. For instance, asymmetries in the direction of gene flow and among loci can elucidate various pre- and postzygotic processes that determine the evolutionary trajectories of the involved lineages. In animals, potential sources of asymmetric introgression include asymmetries in mate choice, driven, for example, by lineage-specific mating preferences and dominance relationships (Rosenfield \& KodricBrown, 2003; Sefc et al., 2015; While et al., 2015), geographic variation in the fitness of immigrants and hybrids (Nosil et al., 2005; Carson et al., 2012), asymmetric range expansions (Johannesen et al., 
2006; but see Zhang, 2014), sex-specific dispersal (Beysard et al., 2012), sex-specific hybrid mortality (Johannesen et al., 2006), and cytonuclear incompatibilities (Arntzen et al., 2009).

In the cichlid fish species Tropheus moorii, mitochondrial and phenotypic variation suggested unidirectional introgression between two genetically distinct color morphs across a major habitat barrier (Sefc et al., 2007). Tropheus are stenotopic inhabitants of the shallow rocky littoral of Lake Tanganyika. High levels of color pattern variation and genetic differentiation among populations are attributed to the presence of numerous dispersal barriers, as the rocky shoreline is frequently interrupted by stretches of sand and by estuaries of rivers and small streams (Egger et al., 2007; Sefc et al., 2007; Koblmüller et al., 2011). Color pattern and genetic differentiation among populations generally increase with geographic distance (which is typically correlated with the number of habitat interruptions), and major habitat barriers often separate phenotypically and genetically highly distinct lineages (Egger et al., 2007). At the very southern tip of Lake Tanganyika, the $6 \mathrm{~km}$ wide stretch of sandy shore in Mbete Bay constitutes such a major barrier to rock-dwelling cichlid species (Fig. 1). In all cichlid species investigated so far, populations show high levels of genetic differentiation across Mbete Bay (Variabilichromis moorii, Duftner et al., 2006; Ophthalmotilapia ventralis, Sefc et al., 2007; Perissodus microlepis, Koblmüller et al., 2009) or do not even share mtDNA haplotypes (Neolamprologus caudopunctatus, Koblmüller et al., 2007; Eretmodus

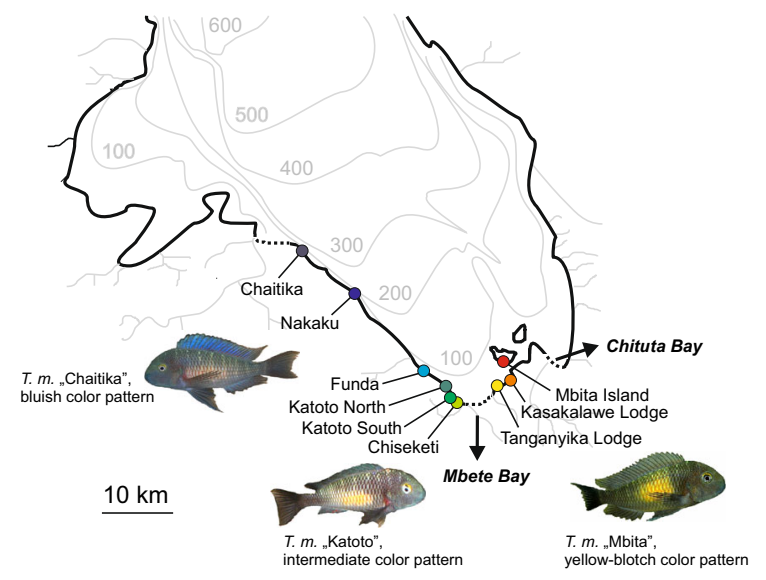

Fig. 1 Map of southern Lake Tanganyika, illustrating origin and color pattern of the sampled populations. Stippled sections of the shoreline indicate large stretches of sandy habitat cyanostictus, Sefc et al., 2007). Many species display distinct color pattern differentiation across the bay, and the distribution range of several species ends at Mbete Bay (Kohda et al., 1996). These observations suggest a long-standing interruption of dispersal in that area. In $T$. moorii, Mbete Bay separates the ranges of two distinct color morphs, a rather uniformly colored bluish-gray morph west of the bay from a morph ornamented with a yellow-blotch on the flank east of the bay (Fig. 1). The two morphs correspond to divergent genetic lineages (Egger et al., 2007; Sefc et al., 2007). Although drops of the lake level have altered the structure of the littoral habitat in geological time frames and launched secondary contact among previously separated populations (Sturmbauer et al., 2005; Egger et al., 2007; Koblmüller et al., 2011; Nevado et al., 2013), Mbete Bay has been considered a permanent barrier to rock-dwelling species (Kohda et al., 1996; Koblmüller et al., 2011). Nonetheless, Tropheus populations immediately west of Mbete Bay carry signatures of introgression from the eastern yellow-blotch lineages. Their color patterns are intermediate to those of the bluish and the yellow-blotch lineages, featuring a yellow-blotch that is smaller and fainter than that of the pure yellow-blotch morph (Kohda et al., 1996; Konings, 2013). Mitochondrial admixture among the two genetic lineages was demonstrated in one of the intermediate populations (30\% yellow blotchspecific mtDNA haplotypes; Sefc et al., 2007). In contrast, yellow-blotch populations east of Mbete Bay showed no evidence of mitochondrial introgression from the bluish lineage (Sefc et al., 2007; Koblmüller et al., 2011). If gene flow across this major barrier was possible at some point, why was it not symmetric?

Several mechanisms that could explain unidirectional gene flow across Mbete Bay appear unlikely given our current knowledge of Tropheus biology. Reciprocal experimental crosses between bluish and yellow-blotch Tropheus produce fertile male and female offspring (C. Sturmbauer, unpublished data), which argues against cytonuclear incompatibilities and sex-specific (female) hybrid mortality that could otherwise explain the lack of introgressed mitochondrial haplotypes in the populations east of Mbete Bay. Lineage-specific dispersal behavior, i.e., a higher dispersal propensity of yellow-blotch than of bluish Tropheus, is rejected by similar and high levels of genetic differentiation among bluish-morph populations west of the bay (Sefc et al., 2007) and among yellow-blotch populations east of the bay (Koblmüller 
et al., 2011), suggesting similar responses to habitat barriers in both morphs. There is no asymmetry in competitive success in contests between the two color morphs (Sefc et al., 2015). Strong drift in the populations east of Mbete Bay, which could have eliminated western haplotypes, is ruled out by the high genetic diversity in these populations (Koblmüller et al., 2011). Strong selection against immigrants or hybrids east, but not west, of Mbete Bay could produce the observed pattern, but the cause for such locationspecific selection remains obscure as habitats and species communities are comparable in the two areas.

A more plausible explanation for unidirectional mitochondrial introgression despite bi-directional migration lies in the mate preferences of the two Tropheus morphs. Two-way mate choice experiments and mating patterns in pond-held groups of bluish and yellow-blotch Tropheus demonstrated that both bluish and yellow-blotch females strongly prefer bluish over yellow-blotch males (Egger et al., 2008; Sefc et al., 2015). Hence, yellow-blotch females migrating into a bluish population would readily mate with bluish males and introduce their mitochondrial genomes into the sink population, whereas bluish females migrating into a yellow-blotch population may not accept yellow-blotch males and fail to spread their mitochondrial genomes. Bluish male immigrants, in contrast, would enjoy high mating success with resident yellow-blotch females and provide for nuclear gene flow from the bluish into the yellow-blotch lineage.
The present study tests this prediction by comparing mitochondrial and nuclear (microsatellite and AFLP) introgression between the bluish and yellow-blotch Tropheus lineages across Mbete Bay. If Tropheus crossed Mbete Bay in both directions, but mitochondrial introgression east of Mbete Bay was prevented by mate choice behavior, we expect signatures of nuclear admixture on both sides of the bay contrasting with asymmetric mitochondrial introgression. In contrast, if the observed asymmetric mitochondrial introgression was due to unidirectional migration of individuals across Mbete Bay, nuclear introgression would also be unidirectional, and nuclear admixture should be evident in the western populations only.

\section{Materials and methods}

Sampling

Populations were sampled at nine locations (Fig. 1) between 2003 and 2009 (2003: Kasakalawe Lodge; 2005: Chaitika (10 individuals), Nakaku, Katoto North, Katoto South (27 ind.), Tanganyika Lodge, Mbita; 2008: Funda; 2009: Chaitika (22 ind.), Katoto South (5 ind.), Chiseketi). Fin clips were preserved in $>95 \%$ ethanol for DNA extraction employing proteinase K digestion and ammonium acetate precipitation (Sambrook \& Russell, 2001). Color pattern type and sample size per population are given in Table 1.

Table 1 Population samples, sample sizes $(n)$, and genetic diversity at mtDNA, AFLP and microsatellite markers.

\begin{tabular}{|c|c|c|c|c|c|c|c|c|c|c|}
\hline \multirow[t]{2}{*}{ Population } & \multirow[t]{2}{*}{ Color pattern type } & \multicolumn{3}{|c|}{ mtDNA } & \multicolumn{3}{|c|}{ AFLP } & \multicolumn{3}{|c|}{ Microsatellites } \\
\hline & & $n$ & $h$ & $H_{\mathrm{E}}$ & $n$ & $P L P(\%)$ & $H_{\mathrm{E}}$ & $n$ & $N A$ & $H_{\mathrm{E}}$ \\
\hline \multicolumn{11}{|l|}{ West of Mbete Bay } \\
\hline Chaitika & Bluish & 32 & 24 & 0.970 & 24 & 37.2 & 0.125 & 36 & 18.25 & 0.846 \\
\hline Nakaku & Bluish & 32 & 20 & 0.962 & 30 & 40.3 & 0.124 & 32 & 16.44 & 0.838 \\
\hline Funda & Bluish & 34 & 23 & 0.970 & 28 & 38.5 & 0.123 & 30 & 15.31 & 0.842 \\
\hline Katoto North & Bluish & 36 & 23 & 0.935 & 29 & 38.8 & 0.121 & 44 & 16.75 & 0.842 \\
\hline Katoto South & Intermediate & 32 & 19 & 0.960 & 28 & 38.9 & 0.122 & 36 & 16.06 & 0.840 \\
\hline Chiseketi & Intermediate & 40 & 17 & 0.935 & 32 & 35.5 & 0.112 & 32 & 15.38 & 0.851 \\
\hline \multicolumn{11}{|l|}{ East of Mbete Bay } \\
\hline Tanganyika Lodge & Yellow-blotch & 28 & 21 & 0.942 & 31 & 37.7 & 0.109 & 30 & 14.69 & 0.816 \\
\hline Kasakalawe Lodge & Yellow-blotch & 30 & 23 & 0.968 & 30 & 38.9 & 0.118 & 30 & 15.00 & 0.835 \\
\hline Mbita & Yellow-blotch & 31 & 23 & 0.974 & 29 & 36.5 & 0.107 & 31 & 14.75 & 0.818 \\
\hline
\end{tabular}

$h$ number of different haplotypes; $H_{\mathrm{E}}$ expected heterozygosity; PLP proportion of polymorphic loci (frequency of less frequent allele $\geq 5 \%$; $N A$ number of alleles 
mtDNA sequence analysis

Amplification and sequencing of the mitochondrial control region followed a standard protocol as in Koblmüller et al. (2011). The amplification was carried out in two PCR reactions with primer pairs L-ProF_Tropheus (Koblmüller et al., 2011) - TDK-D (Lee et al., 1995) and SC-DL (Lee et al., 1995)-TDKDH4-T (Nevado et al., 2009). Sephadex ${ }^{\text {TM }}$ (Amersham) purified Sanger sequencing reaction products (Big Dye Termination Reaction Mix, Applied Biosystems) were run on an ABI 3130xl automatic sequencer (Applied Biosystems). Sequence alignment was done using MUSCLE (Edgar, 2004), and checked by eye in MEGA v.6 (Tamura et al., 2013), and 22 bp of a poly-T region and adjacent positions were removed because of poor signal quality. The final data matrix comprised $797 \mathrm{bp}$. Sequences are deposited in GenBank under the accession numbers KX184420-KX184714.

Diversity indices were calculated in DnaSP v.5.0 (Librado \& Rozas, 2009). Pairwise population differentiation was tested in ARLEQUIN v.3.1 (Excoffier et al., 2005) against corrected $P$ values (Benjamini \& Hochberg, 1995). Identical sequences were collapsed into haplotypes using DNACollapser in FaBox (Villesen, 2007). jModelTest (Posada, 2008) was used to identify the best fitting model of molecular evolution based on Bayesian Information Criterion (BIC). A neighbor-joining (NJ) tree with 1,000 bootstrap replicates was constructed in MEGA.

Chronology of population splitting and past population size dynamics

Parameters of divergence time, migration rates, and effective population sizes were inferred under an isolation with migration model (Hey \& Nielsen, 2004) by coalescence simulations in IMa2 (Hey \& Nielsen, 2007; Hey, 2010). Analyses of pairwise divergence used the following sample units: Chaitika; Nakaku; Mbita Island; Tanganyika Lodge pooled with Kasakalawe Lodge; yellow-blotch lineage individuals from Chiseketi, Katoto South, Katoto North and Funda; bluish lineage individuals from Funda; bluish lineage individuals from Katoto North; and bluish lineage individuals from Katoto South and Chiseketi. Runs were replicated at least two times with different random number seeds. The model employed the HKY model of sequence evolution (Hasegawa et al., 1985). The first 100,000 steps were discarded as burn-in time, and runs were continued until effective sample sizes (ESS) for each estimated parameter were $>200$ (Kuhner, 2009). To translate parameter estimates into absolute values, we assumed an average generation time of 3 years for Tropheus (Egger et al., 2004) and minimum and maximum substitution rates of 0.0178 and 0.0311 per site per MY, respectively, for the whole mitochondrial control region (Nevado et al., 2009). Pairwise divergence times among the above described sample units were illustrated in a NJ tree computed in MEGA. Divergence time between the two major lineages (bluish, yellow-blotch) was inferred by calculating their net divergence in MEGA.

Population size trajectories through time were inferred by means of Bayesian skyline plots (BSPs; Drummond et al., 2005) in BEAST 1.8 (Drummond \& Rambaut, 2007). Separate analyses were carried out for the following sample units: individuals from Chaitika and Nakaku; individuals from Tanganyika Lodge and Kasakalawe Lodge; bluish lineage individuals from Funda, Katoto North, Katoto South and Chiseketi; and yellow-blotch lineage individuals from Funda, Katoto North, Katoto South and Chiseketi. MCMC chains were run for at least $5 \times 10^{6}$ generations, with model parameters and trees sampled every 1,000 generations. We employed the $\mathrm{HKY}+\mathrm{I}+\mathrm{G}$ substitution model (selected as best fitting model by jmodeltest) with a strict molecular clock (as we are looking at intraspecific data; Brown \& Yang, 2011) assuming the same substitution rates as above, and a Bayesian skyline tree prior (Drummond et al., 2005). The first $10 \%$ of generations were discarded as burn-in. Chain convergence to stationarity for all model parameters was assessed in Tracer 1.6 (available from http:// beast.bio.ed.ac.uk/tracer). The various datasets required different run lengths, but all analyses were run until post-burn-in ESS for all parameters exceeded 200. The median and corresponding 95\% highest posterior density (HPD) intervals were visualized with Tracer 1.6 (available from http://beast.bio.ed.ac.uk/tracer).

\section{Nuclear marker analysis}

AFLP genotyping with 18 selective primer combinations was carried out as described in Mattersdorfer et al. (2012). Negative controls consisting of restriction, ligation, and PCR chemicals and 56 replicate samples were included for error rate estimation and genotype scoring in AFLPSCORE 1.4a (Whitlock et al., 2008). 
Per-locus mismatch error rate was $<1.5 \%$. The final data matrix consisted of 1,160 loci. Indices of genetic diversity and differentiation were calculated in AFLPSURV version 1.0 (Vekemans, 2002). Significance levels in multiple tests were assessed against corrected $P$ values (Benjamini \& Hochberg, 1995). Following microsatellite results (see below), Hardy-Weinberg equilibrium was assumed for the estimation of allele frequencies (Zhivotovsky, 1999). Tests for pairwise linkage disequilibrium among AFLP loci were carried out in Arlequin v.3.5 (Excoffier et al., 2005).

The following 16 microsatellite loci were amplified in PCR reactions: UNH2016 (Albertson et al., 2003); UNH908 (Carleton et al., 2002); Pzeb2, Pzeb3 (van Oppen et al., 1997); UNH130, UNH154 (Lee \& Kocher, 1996); UME002, UME003 (Parker \& Kornfield, 1996); TmoM11, TmoM27 (Zardoya et al., 1996); Hchi1, Hchi6, Hchi36 (Maeda et al., 2007); Pmv3, Pmv17 (Crispo et al., 2007); and Ppun9 (Taylor et al., 2002). PCR products were run on an $\mathrm{ABI} 3130 \mathrm{xl}$ automatic sequencer (Applied Biosystems) and sized against GeneScan-500 ROX internal size standard (Applied Biosystems). Allele size calling was carried out in GENEMAPPER v.3.7 (Applied Biosystems). Tests for Hardy-Weinberg and linkage equilibrium and pairwise population differentiation were calculated in ARLEQUIN v.3.1 (Excoffier et al., 2005). There was no significant deviation from HWE after Bonferroni-Holm correction for multiple testing, and all loci were used for further analyses. $P$ values for differentiation tests were corrected with the method of Benjamini \& Hochberg (1995).

Both AFLP and microsatellite data were analyzed in STRUCTURE v.2.3.3 (Pritchard et al., 2000) with $K$ values ranging from 1 to 10 . STRUCTURE output was analyzed with STRUCTURE HARVESTER v.0.6.6 (Evanno et al., 2005; Earl, 2012) to determine the most likely number of genetic clusters. Linkage disequilibrium among AFLP and microsatellite loci was compared among populations as percentage of locus pairs that deviated from equilibrium expectations with $P<0.05$.

\section{Results}

Direction of mitochondrial and nuclear introgression

Variation in mtDNA haplotypes confirmed unidirectional mitochondrial introgression between populations east and west of Mbete Bay (Fig. 2). In populations west of Mbete Bay, the proportions of introgressed "yellow-blotch lineage" haplotypes ranged from $3 \%$ to $40 \%$ and decreased gradually with distance from the bay (Fig. 3a). In contrast, no introgressed "bluish lineage" haplotypes were detected in the populations east of Mbete Bay.

Patterns of admixture in nuclear markers were congruent with the mitochondrial data and likewise indicated unidirectional gene flow across Mbete Bay. The STRUCTURE analysis of the AFLP dataset returned a most likely number of two genetic clusters, corresponding to one bluish and one yellow-blotch clade, with an admixture cline in those populations west of Mbete Bay that contained both mitochondrial lineages (Fig. 4a; Online Resource 1). With microsatellite data, STRUCTURE estimated a most likely number of three genetic clusters (Fig. 4b; Online Resource 1). One cluster represented the two bluish populations most distant from Mbete Bay, which contained only bluish mtDNA haplotypes; the second cluster corresponded to the populations west of Mbete Bay that showed mitochondrial admixture; and the third cluster consisted of the yellow-blotch populations east of Mbete Bay. The Bayesian reconstruction of three genetic clusters from microsatellites contrasts with the two clusters recognized in the AFLP data. Possibly, codominance and the higher mutation rates of microsatellites allow improved detection of genetic structure by the STRUCTURE approach. A STRUCTURE analysis of microsatellite data constrained to $K=2$ revealed an admixture cline that was congruent with the pattern observed with mtDNA and AFLP data (Figs. 3a, 4c).

Nuclear admixture per population was quantified as the average per-individual assignment probability to the bluish lineage ( $q$ values of the STRUCTURE analysis). Nuclear and mtDNA markers consistently reflected a cline in admixture between bluish and yellow-blotch Tropheus genomes in the populations west of Mbete Bay and an abrupt drop in admixture proportions in the populations east of the bay (Fig. 3a).

Diversity and population structure

Both mitochondrial and nuclear markers displayed a high level of genetic diversity within and differentiation among populations (Table 1; Online Resource 2). Overall estimates of population differentiation 


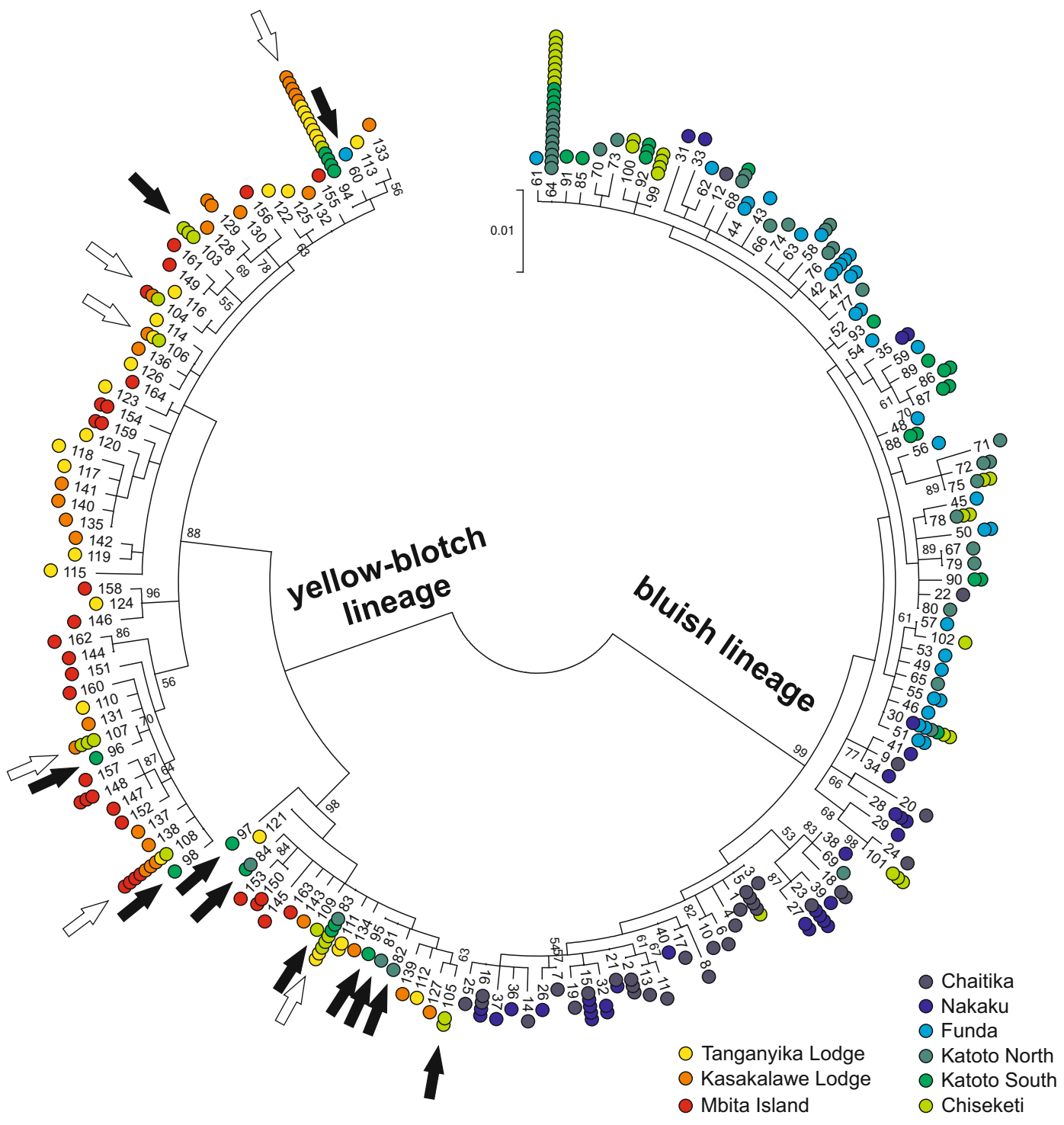

Fig. 2 Relationship among mitochondrial control region haplotypes illustrated in a Neighbor-Joining tree. Sample provenience is color coded. Arrows point out yellow-blotch lineage haplotypes that were detected west of Mbete Bay (white arrows,

were $F_{\mathrm{ST}}=0.059$ for AFLP, $F_{\mathrm{ST}}=0.029$ for microsatellite, $F_{\mathrm{ST}}=0.034$ and $\phi_{\mathrm{ST}}=0.50$ for mtDNA markers, all with $P<0.001$. Pairwise population differentiation (Online Resource 2) was distinct and significant, except for weak or no differentiation across all three marker types between Chaitika and Nakaku as well as between Tanganyika Lodge and Kasakalawe Lodge; in both cases, sampling locations are connected by continuous rocky habitat. haplotype shared with populations east of the bay; black arrows, haplotype private to populations west of the bay). Bootstrap values $>50 \%$ are indicated next to the respective node

Additionally, mitochondrial differentiation estimated by $\phi_{\text {ST }}$ was non-significant in three comparisons among adjacent populations (Katoto North-Funda, Katoto South-Chiseketi, Kasakalawe Lodge-Mbita) and narrowly missed significance based on $F_{\mathrm{ST}}$ estimates in three other population pairs (Katoto SouthKasakalawe Lodge, $P=0.06$; Katoto South-Tanganyika Lodge, $P=0.06$; Katoto North-Chiseketi, $P=0.13)$. 


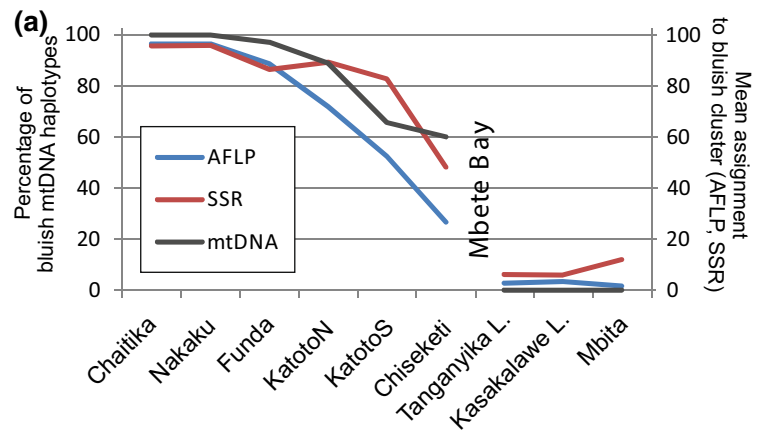

Fig. 3 a Genetic admixture per population in mitochondrial (percent bluish lineage haplotypes in the population) and in nuclear markers (STRUCTURE assignment probabilities to bluish lineage averaged across individuals within populations,

Demographic reconstruction of the admixture event

In the following, "admixed populations" refers to the populations containing haplotypes from both mtDNA lineages (Chiseketi, Katoto North, Katoto South, Funda), as opposed to "pure bluish populations" (Nakaku and Chaitika) and "pure yellow-blotch populations" (Kasakalawe Lodge, Tanganyika Lodge and Mbita; Figs. 2, 3a). Linkage disequilibrium among nuclear loci was not elevated in admixed relative to pure populations (Fig. 3b), and many of the "yellow-blotch lineage" haplotypes found in the admixed populations were not shared with the pure yellow-blotch populations (Fig. 2). These observations and the fact that the stenotopic ecology of Tropheus makes high rates of migration across the $6 \mathrm{~km}$ wide stretch of sand unlikely suggest that the major burst of introgression occurred at some point in the past, when the habitat structure in the area of Mbete Bay allowed migration. IMa2 dated the split of "yellow-blotch lineage" haplotypes found in the admixed populations from the two closest pure yellow-blotch populations (Kasakalawe and Tanganyika Lodge) to a divergence time parameter of 0.489 (mean of four IMa2 runs). Higher divergence time parameter estimates (mean estimates of 0.905-1.016) were obtained between the "bluish lineage" haplotype groups from the different admixed locations west of Mbete Bay (Fig. 5; Online Resource 3 ). This implies that the area occupied by the admixed populations was first colonized by bluish lineage Tropheus when the habitat became available after a

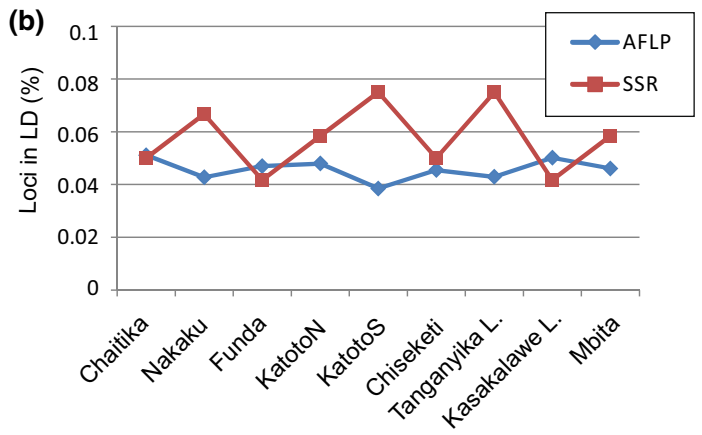

for $K=2$ ). b Linkage disequilibrium per population, as percent of locus pairs that deviated from equilibrium expectations with $P<0.05$

lake lowstand, and then introgressed by yellowblotch-lineage Tropheus migrating from the east. Reconstructions of population sizes through time indicated recent rapid expansions of the pure yellowblotch populations east of Mbete Bay and of the "yellow-blotch lineage" haplotypes in the admixed populations (Fig. 6). In contrast, the pure bluish populations and the "bluish lineage" haplotypes in the admixed populations expanded over a longer period of time, and the "bluish lineage" haplotypes in the admixed populations experienced a recent decline that coincided with growth of the "yellow-blotch lineage" haplotypes in these populations (Fig. 6).

\section{Discussion}

Congruent patterns of mitochondrial and nuclear admixture reject link between mate choice and introgression asymmetry

Congruent unidirectional nuclear and mitochondrial introgression across Mbete Bay rejects the hypothesis that Tropheus migrated in both directions across the bay and mate choice behavior mediated nuclear but not mitochondrial introgression into the yellow-blotch populations east of the bay. Rather, genetic admixture between yellow-blotch and bluish lineages was confined to the locations west of Mbete Bay, where the genetic contribution of the yellow-blotch lineage declined with distance from Mbete Bay. At Mbete Bay, the admixture cline ends with a sharp drop in the proportion of genetic material assigned to the bluish 
(a) $\mathrm{AFLP}, \mathrm{k}=2$

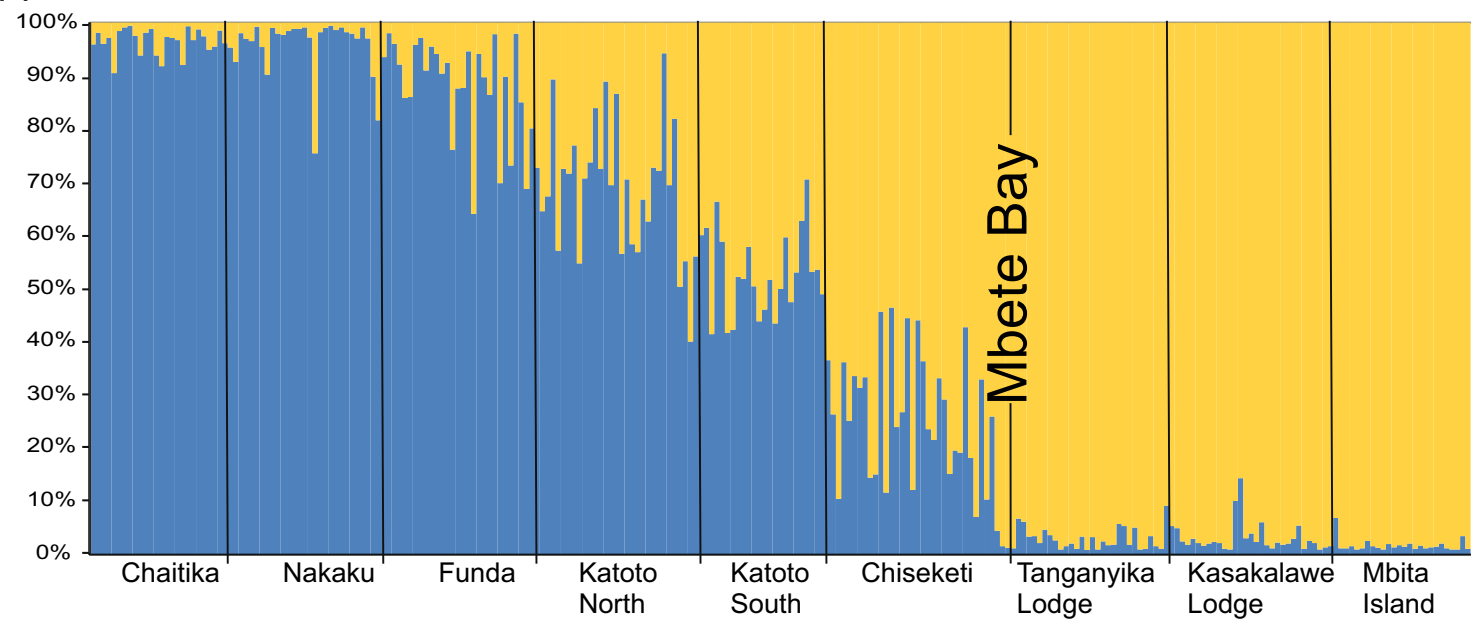

(b) microsatellites, $\mathrm{k}=3$

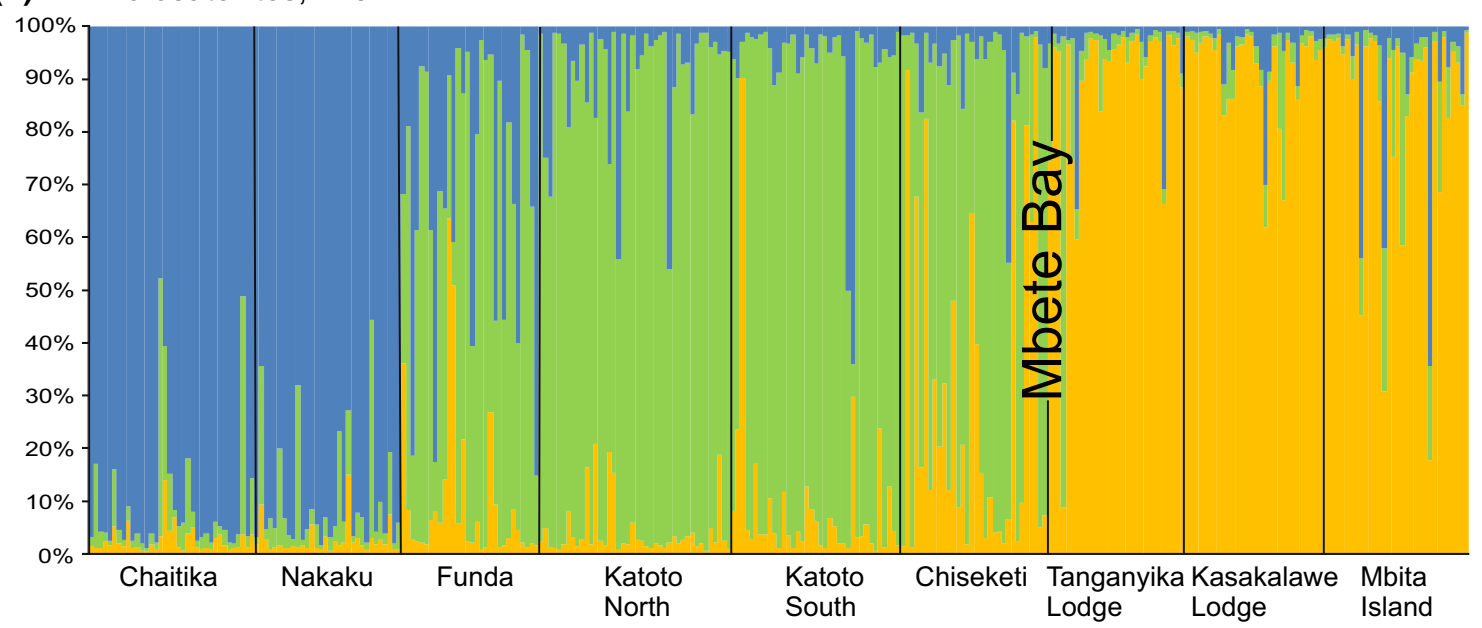

(c) microsatellites, $\mathrm{k}=2$

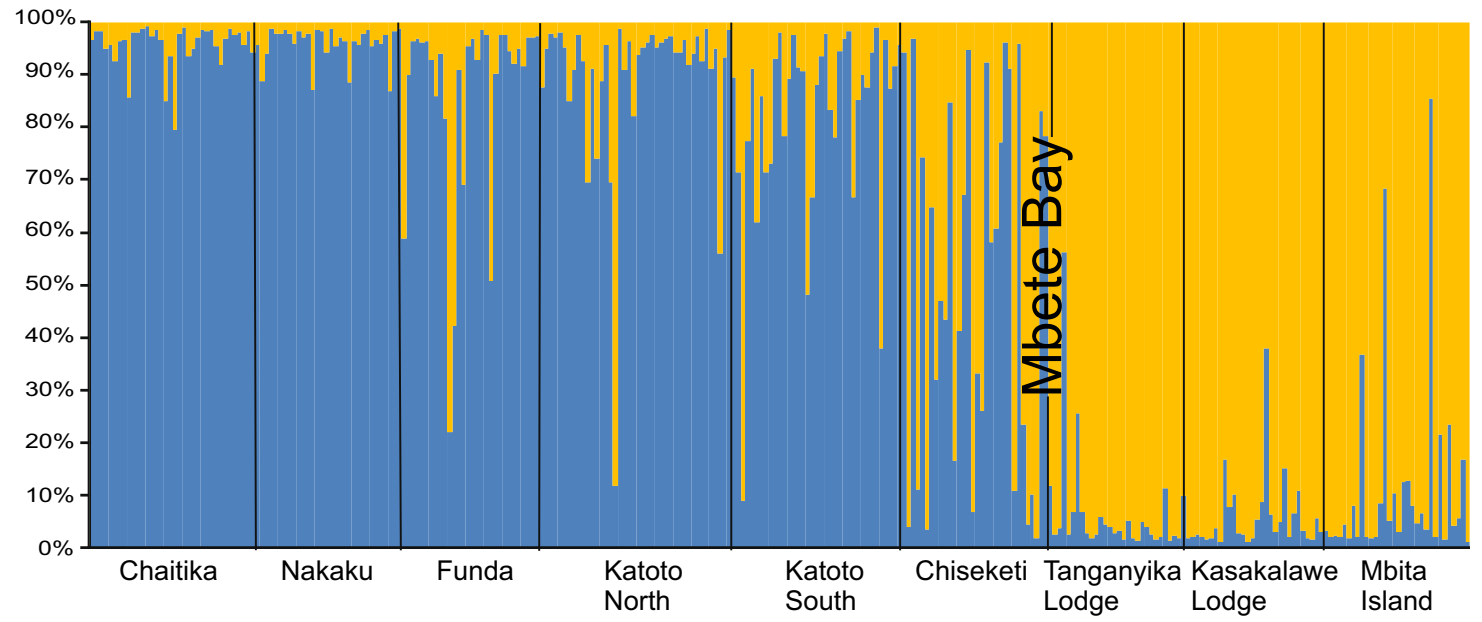


\Fig. 4 Bayesian cluster analysis (STRUCTURE) of the investigated Tropheus moorii populations. Each vertical bar corresponds to one individual and colored sections of each bar represent the individual's assignment probability to the reconstructed genetic clusters. Populations are separated by black lines. a Assignments based on AFLP genotypes for the most likely solution of $K=2$ clusters. b Assignments based on microsatellite genotypes for the most likely solution of $K=3$ clusters. c Assignments into $K=2$ clusters based on microsatellite genotypes

lineage (Fig. 3a). Current migration of the stenotopic rock-dweller across the wide sand barrier is unlikely given that much smaller habitat barriers curb gene flow in this species (Koblmüller et al., 2011; current study), but the genetic data are consistent with a scenario of past migration facilitated by transiently favorable habitat conditions.

An alternative scenario: asymmetric admixture cline shaped by habitat changes

Having rejected asymmetric mate choice as a mechanism causing unidirectional introgression, the question remains why introgression across Mbete Bay occurred in one direction only. A possible explanation involves changes of habitat structure and the population displacements that occurred during lake level fluctuations, which particularly affected the littoral communities of Lake Tanganyika (Cohen et al., 2007; McGlue et al., 2008). Specifically, at the time of secondary contact between the two Tropheus lineages, the area of the presently sandy Mbete Bay may have looked differently and perhaps provided suitable habitat for a westward expansion of yellow-blotch Tropheus. The divergence time estimates in the present study coincide with estimates for splits among yellow-blotch populations between Mbete and Chituta Bay (Koblmüller et al., 2011), which were attributed to the colonization of the area after the lake level had been reduced by $\sim 260 \mathrm{~m}$ during the last glacial maximum at around 30,000 to 15,000 years BP (Cohen et al., 1997; McGlue et al., 2008). In the present as well as in the previous study (Fig. 5; Koblmüller et al., 2011), the estimated population divergence times are older than the paleolimnological dating of the lake level rise. This is expected because substitution rate estimates that are based on an ancient event (in our case, 1MYA; Nevado et al., 2009) are bound to overestimate the age of recent splits (Ho et al., 2005). With the southward expansion of the lake's shoreline that accompanied the rising lake level (Fig. 1; McGlue et al., 2008), bluish Tropheus colonized the shoreline west of Mbete Bay from their northern retreat, whereas yellow-blotch Tropheus moved into the area east of Mbete Bay from the opposite direction. Habitat structure during the lake level rise may have allowed yellow-blotch Tropheus to expand their range along rocky habitat until they came into contact with the bluish Tropheus. After an admixture zone was formed by introgression between the two lineages, progressing sedimentation of Mbete

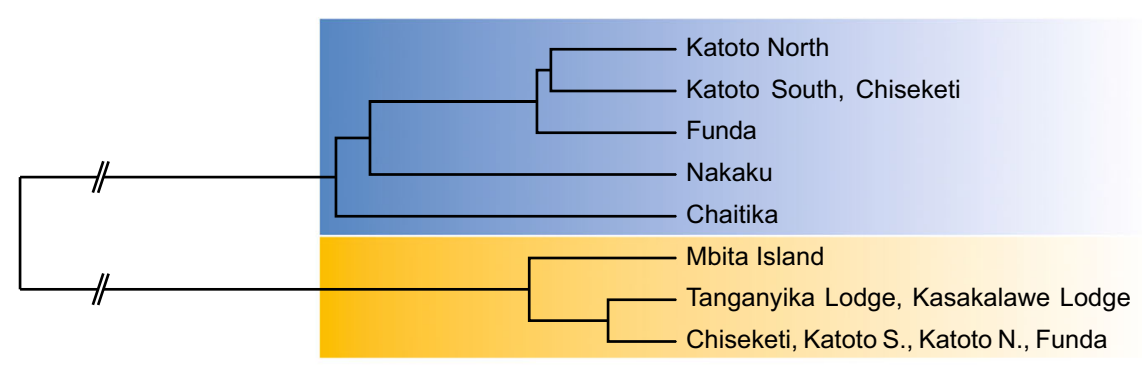

bluish lineage
haplotypes

yellow-blotch lineage haplotypes

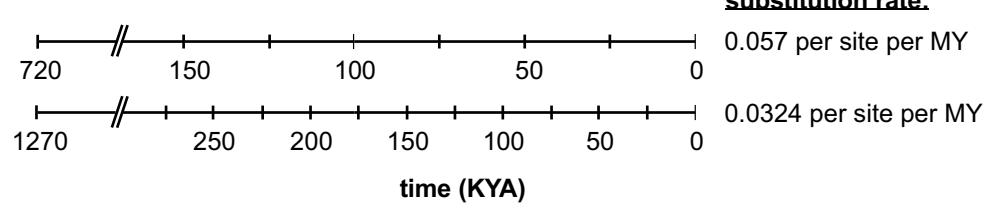

Fig. 5 Chronology of population splitting reconstructed from mtDNA data. Samples from admixed populations were grouped by haplotype lineage. Pairwise population divergence was modeled in IMa2; splitting time between the two major lineages was estimated as net divergence in MEGA 
Fig. 6 Bayesian skyline plots of population sizes through time. Thick and thin lines represent the median and $95 \%$ HPD intervals, respectively. The $y$-axis represents the population size parameter (female effective population size times the mutation rate)
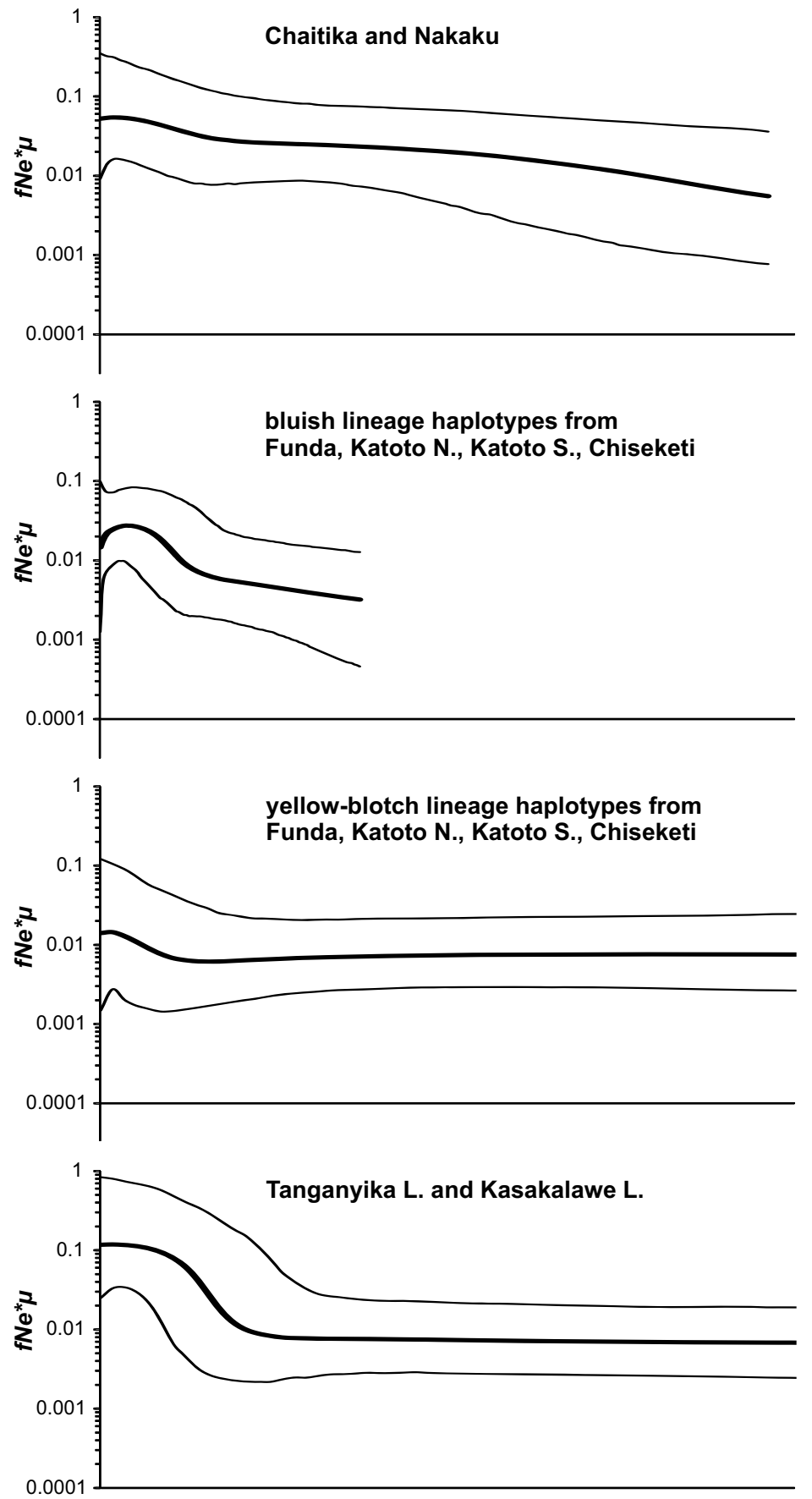

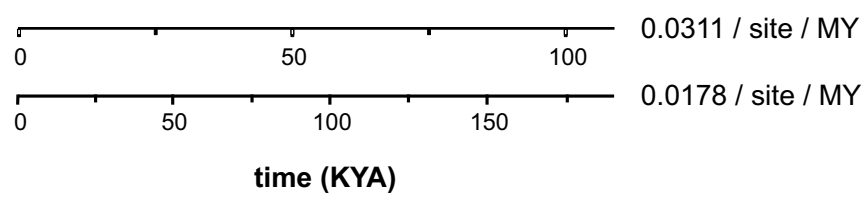


Bay may then have caused local extinctions of Tropheus populations, which may have truncated the eastern section of the admixture cline and shaped the current asymmetric pattern. This scenario is contingent on the transient inhabitability of the Mbete Bay area for a rock-dwelling fish, which is not altogether unlikely given that a change in the lake level is expected to redistribute the sediment and alter the sedimentation system (Andy Cohen, pers. comm.). Although Mbete Bay represents a divide between genetic and phenotypic clusters for several cichlid species (Kohda et al., 1996; Duftner et al., 2006; Koblmüller et al., 2007; Sefc et al., 2007; Koblmüller et al., 2009), haplotype networks of some rock-dwelling species show signatures of introgression between the genetic lineages found east and west of bay (Perissodus microlepis: Koblmüller et al., 2009; Variabilichromis moorii: Duftner et al., 2006; Eretmodus cyanostictus, Ophthalmotilapia ventralis: Sefc et al., 2007), although never to that extent as detected in Tropheus moorii.

Demographic expansion of yellow-blotch lineage haplotypes in the admixed populations

The demographic expansion of the "yellow-blotch lineage" haplotype group and simultaneous decline of the "bluish lineage" clade in the admixed populations suggest that reproductive success of females carrying the yellow-blotch haplotype exceeded that of females carrying the bluish haplotype. Selection favoring one haplotype lineage may have a physiological underpinning, for instance, associated with energy metabolism (Shen et al., 2010), but could also be related to the asymmetric mate preferences that were initially hypothesized to drive unidirectional mitochondrial introgression. During admixture, a declining mating propensity of the discriminating bluish females in the face of an increasing frequency of intermediate Tropheus phenotypes would have been contrasted with ready reproduction by yellowblotch females, which could have caused decline and expansion, respectively, of the two mitochondrial lineages. Finally, lineage-specific differences in female fecundity could also produce the observed pattern.

\section{Conclusion}

Patterns of unidirectional introgression between species or geographically separated clades are frequently observed in genetic studies, but the mechanisms behind the asymmetry are seldom inferred conclusively (Zhang, 2014). Exceptions are cases that involve geographic barriers that can clearly be negotiated in only one direction, such as waterfalls or water currents for aquatic organisms (Papetti et al., 2012; Schilthuizen et al., 2012; Schenekar et al., 2014; Reis et al., 2015). In the absence of such external sources of asymmetry, suggested causes for asymmetry typically include mate choice (Nevado et al., 2011; Pons et al., 2014) and cytonuclear incompatibilities (Arntzen et al., 2009; Nevado et al., 2011). In the present example, the pattern of unidirectional introgression can be explained on the basis of habitat changes, which first facilitated the development of a symmetric admixture zone and then shaped asymmetry by causing local extinctions and cessation of gene flow. Habitat structure and dynamics have already previously been suggested to be important factors in the evolution and diversification of Tropheus (Egger et al., 2007, 2010; Koblmüller et al., 2011; Sefc et al., 2015; Van Steenberge et al., 2015), and the present study supports this by once again implying habitat structure as a primary determinant of population structure and introgression patterns. In this respect, Tropheus may be representative of littoral rock dwellers, or habitat specialists, that find themselves at the mercy of the dynamics of their preferred habitat.

Acknowledgments We thank Lawrence Makasa, Danny Sinyinza, and all the other people at the Mpulungu Station of the Ministry of Agriculture and Cooperatives, Republic of Zambia for their help and hospitality during fieldwork. We further thank Andy Cohen for sharing his insights on the effect of lake level fluctuations on shoreline habitat with us. The work was supported by the Austrian Science Fund (FWF) grant number P20883-B16 to KMS. Open access funding provided by University of Graz.

Open Access This article is distributed under the terms of the Creative Commons Attribution 4.0 International License (http:// creativecommons.org/licenses/by/4.0/), which permits unrestricted use, distribution, and reproduction in any medium, provided you give appropriate credit to the original author(s) and the source, provide a link to the Creative Commons license, and indicate if changes were made.

\section{References}

Albertson, R. C., J. T. Streelman \& T. D. Kocher, 2003. Directional selection has shaped the oral jaws of Lake 
Malawi cichlid fishes. Proceedings of the National Academy of Science USA 100: 5252-5257.

Arntzen, J. W., R. Jehle, F. Bardakci, T. Burke \& G. P. Wallis, 2009. Asymmetric viability of reciprocal-cross hybrids between crested and marbled newts (Triturus cristatus and T. marmoratus). Evolution 63: 1191-1202.

Benjamini, Y. \& Y. Hochberg, 1995. Controlling the false discovery rate: a practical and powerful approach to multiple testing. Journal of the Royal Statistical Society B 57: 289-300.

Beysard, M., N. Perrin, M. Jaarola, G. Heckel \& P. Vogel, 2012. Asymmetric and differential gene introgression at a contact zone between two highly divergent lineages of field voles (Microtus agrestis). Journal of Evolutionary Biology 25: 400-408.

Brown, R. P. \& Z. Yang, 2011. Rate variation and estimation of divergence times using strict and relaxed clocks. BMC Evolutionary Biology 11: 271.

Carleton, K. L., J. T. Streelman, B. Lee, N. Garnhart, M. Kidd \& T. D. Kocher, 2002. Rapid isolation of CA microsatellites from the tilapia genome. Animal Genetics 33: 140-144.

Carson, E. W., M. Tobler, W. Minckley, R. J. Ainsworth \& T. E. Dowling, 2012. Relationships between spatio-temporal environmental and genetic variation reveal an important influence of exogenous selection in a pupfish hybrid zone. Molecular Ecology 21: 1209-1222.

Cohen, A. S., K.-E. Lezzar, J.-J. Tiercelin \& M. Soreghan, 1997. New palaeogeographic and lake-level reconstructions of Lake Tanganyika: implications for tectonic, climatic and biological evolution in a rift lake. Basin Research 9: 107-132.

Cohen, A. S., J. R. Stone, K. R. M. Beuning, L. E. Park, P. N. Reinthal, D. Dettman, C. A. Scholz, T. C. Johnson, J. W. King, M. R. Talbot, E. T. Brown \& S. J. Ivory, 2007. Ecological consequences of early Late Pleisotcene megadroughts in tropical Africa. Proceedings of the National Academy of Sciences of the USA 104: 16422-16427.

Crispo, E., C. Hagen, T. Glenn, G. Geneau \& L. J. Chapman, 2007. Isolation and characterization of tetranucleotide microsatellite markers in a mouth-brooding haplochromine cichlid fish (Pseudocrenilabrus multicolor victoriae) from Uganda. Molecular Ecology Notes 7: 1293-1295.

Drummond, A. J. \& A. Rambaut, 2007. BEAST: Bayesian evolutionary analysis by sampling trees. BMC Evolutionary Biology 7: 214.

Drummond, A. J., A. Rambaud, B. Shapiro \& O. G. Pybus, 2005. Bayesian coalescent inference of past population dynamics from molecular sequences. Molecular Biology and Evolution 22: 1185-1192.

Duftner, N., K. M. Sefc, S. Koblmüller, B. Nevado, E. Verheyen, H. Phiri \& C. Sturmbauer, 2006. Distinct population structure in a phenotypically homogeneous rock-dwelling cichlid fish from Lake Tanganyika. Molecular Ecology 15: 2381-2395.

Earl, D. A., 2012. STRUCTURE HARVESTER: a website and program for visualizing STRUCTURE output and implementing the Evanno method. Conservation Genetics Resources 4: 359-361.

Edgar, R. C., 2004. MUSCLE: multiple sequence alignment with high accuracy and high throughput. Nucleic Acids Research 32: 1792-1797.
Egger, B., M. Meekan, W. Salzburger, L. Mwape, L. Makasa, R. Shapola \& C. Sturmbauer, 2004. Validation of the periodicity of increment formation in the otoliths of a cichlid fish from Lake Tanganyika, East Africa. Journal of Fish Biology 64: 1-13.

Egger, B., S. Koblmüller, C. Sturmbauer \& K. M. Sefc, 2007. Nuclear and mitochondrial data reveal different evolutionary processes in the Lake Tanganyika cichlid genus Tropheus. BMC Evolutionary Biology 7: 137.

Egger, B., B. Obermüller, E. Eigner, C. Sturmbauer \& K. M. Sefc, 2008. Assortative mating preferences between colour morphs of the endemic Lake Tanganyika cichlid genus Tropheus. Hydrobiologia 615: 37-48.

Egger, B., K. Mattersdorfer \& K. M. Sefc, 2010. Variable discrimination and asymmetric preferences in laboratory tests of reproductive isolation between cichlid colour morphs. Journal of Evolutionary Biology 23: 433-439.

Evanno, G., S. Regnaut \& J. Goudet, 2005. Detecting the number of clusters of individuals using the software STRUCTURE: a simulation study. Molecular Ecology 14: 2611-2620.

Excoffier, L., G. Laval \& S. Schneider, 2005. Arlequin (version 3.0): an integrated software package for population genetics data analysis. Evolutionary Bioinformatics Online 1: 47-50.

Hasegawa, M., H. Kishino \& T. Yano, 1985. Dating of the human-ape splitting by a molecular clock of mitochondrial DNA. Journal of Molecular Evolution 22: 160-174.

Hey, J., 2010. Isolation with migration models for more than two populations. Molecular Biology and Evolution 27: 905-920.

Hey, J. \& R. Nielsen, 2004. Multilocus methods for estimating population sizes, migration rates and divergence time, with applications to the divergence of Drosophila pseudoobscura and D. persimilis. Genetics 167: 747-760.

Hey, J. \& R. Nielsen, 2007. Integration within the Felsenstein equation for improved Markov chain Monte Carlo methods in population genetics. Proceedings of the National Academy of Science USA 104: 2785-2790.

Ho, S. Y., M. J. Phillips, A. Cooper \& A. J. Drummond, 2005. Time dependency of molecular rate estimates and systematic overestimation of recent divergence times. Molecular Biology and Evolution 22: 1561-1568.

Johannesen, J., B. Johannesen, E. Griebeler, I. Baran, M. Tunc, A. Kiefer \& M. Veith, 2006. Distortion of symmetrical introgression in a hybrid zone: evidence for locus-specific selection and uni-directional range expansion. Journal of Evolutionary Biology 19: 705-716.

Koblmüller, S., K. M. Sefc, N. Duftner, M. Warum \& C. Sturmbauer, 2007. Genetic population structure as indirect measure of dispersal ability in a Lake Tanganyika cichlid. Genetica 130: 121-131.

Koblmüller, S., N. Duftner, K. M. Sefc, U. Aigner, M. Rogetzer \& C. Sturmbauer, 2009. Phylogeographic structure and gene flow in the scale-eating cichlid Perissodus microlepis (Teleostei, Perciformes, Cichlidae) in southern Lake Tanganyika. Zoologica Scripta 38: 257-268.

Koblmüller, S., W. Salzburger, B. Obermüller, E. Eigner, C. Sturmbauer \& K. M. Sefc, 2011. Separated by sand, fused by dropping water: habitat barriers and fluctuating water levels steer the evolution of rock-dwelling cichlid 
populations in Lake Tanganyika. Molecular Ecology 20: 2272-2290.

Kohda, M., Y. Yanagisawa, T. Sato, K. Nakaya, Y. Niimura, K. Matsumoto \& H. Ochi, 1996. Geographical colour variation in cichlid fishes at the southern end of Lake Tanganyika. Environmental Biology of Fishes 45: 237-248.

Konings, A., 2013. Tropheus in Their Natural Habitat. Cichlid Press, El Paso, Texas.

Kuhner, M. K., 2009. Coalescent genealogy samplers: windows into population history. Trends in Ecology \& Evolution 24: 86-93.

Lee, W. \& T. D. Kocher, 1996. Microsatellite DNA markers for genetic mapping in Oreochromis niloticus. Journal of Fish Biology 49: 169-171.

Lee, W., J. Conroy, W. H. Howell \& T. D. Kocher, 1995. Structure and evolution of teleost mitochondrial control regions. Journal of Molecular Evolution 41: 54-66.

Librado, P. \& J. Rozas, 2009. DnaSP v5: a software for comprehensive analysis of DNA polymorphism data. Bioinformatics (Oxford, England) 25: 1451-1452.

Maeda, K., H. Takeshima, S. Mizoiri, N. Okada, M. Nishida \& H. Tachida, 2007. Isolation and characterization of microsatellite loci in the cichlid fish in Lake Victoria, Haplochromis chilotes. Molecular Ecology Notes 8: 428-430.

Mattersdorfer, K., S. Koblmüller \& K. M. Sefc, 2012. AFLP genome scans suggest divergent selection on colour patterning in allopatric colour morphs of a cichlid fish. Molecular Ecology 21: 3531-3544.

McGlue, M. M., K. E. Lezzar, A. S. Cohen, J. M. Russell, J.-J. Tiercelin, A. A. Felton, E. Mbede \& H. H. Nkotagu, 2008. Seismic record of late Pleistocene aridity in Lake Tanganyika, tropical East Africa. Journal of Palaeolimnology 40: 635-653.

Nevado, B., S. Koblmüller, C. Sturmbauer, J. Snoeks, J. UsanoAlemany \& E. Verheyen, 2009. Complete mitochondrial DNA replacement in a Lake Tanganyika cichlid fish. Molecular Ecology 18: 4240-4255.

Nevado, B., V. Fazalova, T. Backeljau, M. Hanssens \& E. Verheyen, 2011. Repeated unidirectional introgression of nuclear and mitochondrial DNA between four congeneric Tanganyikan cichlids. Molecular Biology and Evolution 28: 2253-2267.

Nevado, B., S. Mautner, C. Sturmbauer \& E. Verheyen, 2013. Water-level fluctuations and metapopulation dynamics as drivers of genetic diversity in populations of three Tanganyikan cichlid fish species. Molecular Ecology 22: 3933-3948.

Nosil, P., T. H. Vines \& D. J. Funk, 2005. Reproductive isolation caused by natural selection against immigrants from divergent habitats. Evolution 59: 705-719.

Papetti, C., J. M. Pujolar, M. Mezzavilla, M. La Mesa, J. Rock, L. Zane \& T. Patarnello, 2012. Population genetic structure and gene flow patterns between populations of the Antarctic icefish Chionodraco rastrospinosus. Journal of Biogeography 39: 1361-1372.

Parker, A. \& I. Kornfield, 1996. Polygynandry in Pseudotropheus zebra, a cichlid fish from Lake Malawi. Environmental Biology of Fishes 47: 345-352.

Pons, J., S. Sonsthagen, C. Dove \& P. Crochet, 2014. Extensive mitochondrial introgression in North American Great
Black-backed Gulls (Larus marinus) from the American Herring Gull (Larus smithsonianus) with little nuclear DNA impact. Heredity 112: 226-239.

Posada, D., 2008. jModelTest: phylogenetic model averaging. Molecular Biology and Evolution 25: 1253-1256.

Pritchard, J. K., M. Stephens \& P. Donnelly, 2000. Inference of population structure using multilocus genotype data. Genetics 155: 945-959.

Reis, K., P. Venere, I. Sampaio, P. Rêgo, M. Vallinoto \& I. Souza, 2015. Downstairs gene flow: the effects of a linear sequence of waterfalls on the only population of the endangered minnow Astyanax xavante. Journal of Fish Biology 87: 754-762.

Rosenfield, J. \& A. Kodric-Brown, 2003. Sexual selection promotes hybridization between Pecos pupfish, Cyprinodon pecosensis and sheepshead minnow, C. variegatus. Journal of Evolutionary Biology 16: 595-606.

Sambrook, J. \& D. W. Russell, 2001. Molecular Cloning: A Laboratory Manual, 3rd ed. Cold Springs Harbor Laboratory Press, Cold Springs Harbor, NY.

Schenekar, T., E. Lerceteau-Köhler \& S. Weiss, 2014. Finescale phylogeographic contact zone in Austrian brown trout Salmo trutta reveals multiple waves of post-glacial colonization and a pre-dominance of natural versus anthropogenic admixture. Conservation Genetics 15: 561-572.

Schilthuizen, M., E. M. Rutten \& M. Haase, 2012. Small-scale genetic structuring in a tropical cave snail and admixture with its above-ground sister species. Biological Journal of the Linnean Society 105: 727-740.

Sefc, K. M., S. Baric, W. Salzburger \& C. Sturmbauer, 2007. Species-specific population structure in rock-specialized sympatric cichlid species in Lake Tanganyika, East Africa. Journal of Molecular Evolution 64: 33-49.

Sefc, K. M., C. M. Hermann, B. Steinwender, H. Brindl, H. Zimmermann, K. Mattersdorfer, L. Postl, L. Makasa, C. Sturmbauer \& S. Koblmüller, 2015. Asymmetric dominance and asymmetric mate choice oppose premating isolation after allopatric divergence. Ecology and Evolution 5: 1549-1562.

Shen, Y., L. Liang, Z. Zhu, W. Zhou, D. M. Irwin, Y. Zhang \& D. M. Hillis, 2010. Adaptive evolution of energy metabolism genes and the origin of flight in bats. Proceedings of the National Academy of Sciences of the United States of America 107: 8666-8671.

Sturmbauer, C., S. Koblmüller, K. M. Sefc \& N. Duftner, 2005. Phylogeographic history of the genus Tropheus, a lineage of rock-dwelling cichlid fishes endemic to Lake Tanganyika. Hydrobiologia 542: 335-366.

Tamura, K., G. Stecher, D. Peterson, A. Filipski \& S. Kumar, 2013. MEGA6: molecular evolutionary genetics analysis version 6.0. Molecular Biology and Evolution 30: 2725-2729.

Taylor, M. I., F. Meardon, G. F. Turner, O. Seehausen, H. D. J. Mrosso \& C. Rico, 2002. Characterization of tetranucleotide microsatellite loci in a Lake Victorian, haplochromine cichlid fish: a Pundamilia pundamilia $\mathrm{x}$ Pundamilia nyererei hybrid. Molecular Ecology Notes 2: 443-445.

van Oppen, M. J. H., C. Rico, J. C. Deutsch, G. F. Turner \& G. M. Hewitt, 1997. Isolation and characterization of 
microsatellite loci in the cichlid fish Pseudotropheus zebra. Molecular Ecology 6: 387-388.

Van Steenberge, M., M. P. Vanhove, F. C. Breman \& J. Snoeks, 2015. Complex geographical variation patterns in Tropheus duboisi Marlier, 1959 (Perciformes, Cichlidae) from Lake Tanganyika. Hydrobiologia 748: 39-60.

Vekemans, X., 2002. AFLP-surv version 1.0. Distributed by the author. Laboratoire de Génétique et Ecologie Végétale, Université Libre de Bruxelles, Belgium: 16.

Villesen, P., 2007. FaBox: an online toolbox for fasta sequences. Molecular Ecology Notes 7: 965-968.

While, G. M., S. Michaelides, R. J. Heathcote, H. E. MacGregor, N. Zajac, J. Beninde, P. Carazo, G. Pérez i de Lanuza, R. Sacchi \& M. A. Zuffi, 2015. Sexual selection drives asymmetric introgression in wall lizards. Ecology Letters 18: 1366-1375.

Whitlock, R., H. Hipperson, M. Mannarelli, R. K. Butlin \& T. Burke, 2008. An objective, rapid and reproducible method for scoring AFLP peak-height data that minimizes genotyping error. Molecular Ecology Resources 8: 725-735.

Zardoya, R., D. M. Vollmer, C. Craddock, J. T. Streelman, S. Karl \& A. Meyer, 1996. Evolutionary conservation of microsatellite flanking regions and their use in resolving the phylogeny of cichlid fishes (Pisces: Perciformes). Proceedings of the Royal Society of London Series B 263: 1589-1598.

Zhang, D., 2014. Demographic model of admixture predicts symmetric introgression when a species expands into the range of another: a comment on Currat et al. (2008). Journal of Systematics and Evolution 52: 35-39.

Zhivotovsky, L. A., 1999. Estimating population structure in diploids with multilocus dominant DNA markers. Molecular Ecology 8: 907-913. 